\title{
Responsive site on the thrombospondin-1 promotor to down- regulation by phorbol 12-myristate 13-acetate in porcine aortic endothelial cells
}

\author{
Soo-A Kim ${ }^{1}$ and Kyong-Ja Hong ${ }^{1,2}$ \\ ${ }^{1}$ Department of Biochemistry, College of Medicine, \\ The Catholic University of Korea, 505 Banpo-dong, \\ Socho-gu, Seoul 137-701, Korea \\ ${ }^{2}$ Corresponding author: Tel, +82-2-590-1183; Fax, +82-2-596-4435; \\ E-mail, kjhong@cmc.cuk.ac.kr
}

Accepted 18 September 2000

Abbreviations: TSP-1, thrombospondin-1; PMA, phorbol 12-myristate 13-acetate; PAE, porcine aortic endothelial; EMSA, electrophoretic mobility shift assay; PKC, protein kinase C; fpu, footprint units; PMSF, phenymethylsulfonyl fluoride

\begin{abstract}
Thrombospondin-1 (TSP-1), a multifunctional extracellular matrix protein, inhibits neovascularization and is implicated in the regression of tumor growth and metastasis. We found that the synthesis of TSP1 in porcine aortic endothelial (PAE) cells was decreased in a dose-dependent manner by phorbol 12myristate 13-acetate (PMA) treatment in porcine aortic endothelial (PAE) cells. In this study, a responsive site on the TSP-1 promotor affected by PMA treatment in PAE was characterized. The level of TSP-1 mRNA was also decreased by PMA after $1 \mathrm{~h}$ and persisted that way for at least $24 \mathrm{~h}$. PMA treatment and c-Jun overexpression suppressed the transcription of TSP-1 promotor-luciferase reporter gene. A deletion between -767 and -657 on the TSP1 promotor neutralized the PMA-induced down-regulation. In addition, oligo a (-767 -723) was responsive to PMA-induced repression, while oligo b (-734 $\sim-689)$ and c (-700 -656) was not. Electrophoretic mobility shift assays showed that this PMA responsive element specifically bound a nuclear protein and that the binding activity was diminished by PMA treatment in PAE cells but not in Hep 3B cells. In supershift assay, potential regulatory elements in this region, SP1 and GATA-1, were not responsive to the inhibition of TSP-1 expression by PMA. Our results suggest that the repression of TSP-1 synthesis by PMA is mediated by blocking a particular unknown nuclear protein binding to the responsive site (-767 -735), which is regulated by c-Jun.
\end{abstract}

Keywords: Thrombospondin-1; PMA; protein kinase C; c-Jun; AP-1

\section{Introduction}

Thrombospondin-1 (TSP-1) is a homotrimeric extracellular matrix glycoprotein of $450 \mathrm{kD}$ (Lawler, 1986; Bornstein, 1992). It is synthesized and secreted by the wide range of cells including fibroblasts, smooth muscle cells, macrophages, endothelial cells, and transformed cells (Varani et al., 1989; Clezardin, 1993). Each monomer (180 kD) has functional domains capable of binding to many extracellular matrices and a variety of other proteins including several receptors, enzymes, and cytokines (Bornstein, 1995). Because of these multiple interactions, TSP-1 has been implicated in a number of biological processes such as development, inflammation, wound healing, tumor growth and metastasis (Mosher, 1990; Bornstein, 1992; Lahav, 1993).

The transcription factor AP-1 forms either homodimers or heterodimers with members of the Jun family (c-Jun, Jun $B$, and Jun $D$ ) or with proteins of the Jun and Fos (c-Fos, Fos B, Fra 1, and Fra 2) families (Angel and Karin, 1991). Among them, C-Jun is the major component of AP-1 complexes with c-Fos (Bohman et al., 1987; Angel et al., 1988). AP-1 is activated following stimulation by protein kinase $C(P K C)$, and it regulates the expression of AP-1 responsive target genes.

We observed that PMA significantly induced the expression of TSP-1 in hepatocarcinoma Hep 3B cells and up-regulation of TSP-1 synthesis following PMA treatment was mediated by an increased AP-1 binding activity via PKC activation. The functional AP-1 binding site was also identified and was activated upon increased cJun expression. In addition, PMA was reported to reduce TSP-1 expression in human monocytes (Yesner et al., 1996) and c-jun lead to the repression of TSP-1 in rat fibroblasts (Mettouchi et al., 1994; Dejong et al., 1999). We also found that PMA inhibited TSP-1 synthesis in porcine aortic endothelial (PAE) cells but not on Hep 3B cells.

Based on cell type specific expression of TSP-1, the mechanism of TSP-1 gene expression in PAE cells was examined. A dose-dependent inhibition of TSP-1 expression by PMA was observed in PAE cells. The responsive element for the PMA-induced inhibition was contained in the region between -767 and -735 of the TSP-1 gene promoter. We found that this cis element played 
an important role in the PMA-modulated down-regulation of the TSP-1 gene expression in PAE cells and that the c-Jun-induced repression of TSP-1 expression did not require direct binding of C-Jun to the TSP-1 promoter.

\section{Materials and Methods}

\section{Cell lines and culture}

Porcine aortic endothelial (PAE) cells were provided by Kim H. P. (KNIH) and maintained in M199 medium (Gibco Laboratories, Grand Island, N.Y.) containing $10 \%$ heatinactivated fetal calf serum. Human hepatocarcinoma Hep 3B cells were obtained from the American Type Culture Collection (Rockville, MD) and cultured in RPMI 1640 medium. Cells were maintained at $37^{\circ} \mathrm{C}$ under $5 \% \mathrm{CO}_{2}$. All experiments were performed in duplicate or triplicate hereafter.

\section{Western blot analysis}

PAE cells $\left(2 \times 10^{5}\right.$ cells $\left./ \mathrm{ml}\right)$ were plated in 6 -well culture plates. Two days later, the cells were washed twice with calcium/magnesium free-phosphate buffered saline (CMFPBS, pH 7.2) and incubated at $37^{\circ} \mathrm{C}$ with serum free M199 in the presence or absence of PMA. After $24 \mathrm{~h}$, the culture supernatants were harvested and concentrated in order to examine the level of TSP-1 secreted. Two milliliters of culture supernatants were concentrated using Centricon-50 (Amicon, USA) at 3,000 $\mathrm{g}$ for $20 \mathrm{~min}$ in the presence of protease inhibitors-PMSF $(1 \mu \mathrm{g} / \mathrm{ml})$, leupeptin $(1 \mu \mathrm{g} / \mathrm{ml})$ and aprotinin $(2 \mu \mathrm{g} / \mathrm{ml})$. The concentrates were mixed with an equal volume of $2 \times$ sample buffer (Laemmli, 1970) and electrophoresed through a $7.5 \%$ SDS-polyacrylamide gel, and the separated proteins were transferred onto a nitrocellulose membrane. After blocking with $5 \%$ skim milk, the membrane was incubated for $1.5 \mathrm{~h}$ with anti-TSP-1 antibody (1:1000, Calbiochem, San Diego, CA) and washed (four times for 5 min each) with TBS buffer containing $0.1 \%$ Tween 20 (TTBS). The membrane was then incubated with antirabbit peroxidase-conjugated antibody $(1: 4000$, Sigma Co., St. Louis, MO) as the secondary antibody for $1 \mathrm{~h}$ and washed again with TTBS. TSP-1 was visualized using an ECL detection kit (Amersham, Buckinghamshire, $\mathrm{U}$. $\mathrm{K}$.). For Western blot analysis of c-Fos and c-Jun, nuclear extracts $(30 \mu \mathrm{g})$ were prepared (Schreiber et al., 1989 ) and analyzed after $12.5 \%$ SDS-PAGE. These blots were incubated with anti-c-Fos or anti-c-Jun antibody (1: 1000, Oncogene Research Products, Cambridge, MA) for $1.5 \mathrm{~h}$.

\section{Northern blot analysis}

Cells $\left(2 \times 10^{5}\right.$ cells $\left./ \mathrm{ml}\right)$ were seeded into $60 \mathrm{~mm}$ dishes. After two days, the cells were washed twice with CMF-
PBS and incubated at $37^{\circ} \mathrm{C}$ with serum free M199. Cells were treated with PMA for the indicated times and total cellular RNA was isolated using RNA STAT-60 (TELTEST, INC., Friendswood, TX). The RNA samples (15 $\mu \mathrm{g})$ were then electrophoresed through a $1 \%$ agaroseformaldehyde gel and transferred to a nylon membrane. The blots were hybridized with a digoxigenin (DIG)labeled probe and detected by an immunochemical method using a DIG chemiluminescence detection kit (Boehringer Mannheim, Germany). The probe encoding the sequence of TSP-1 was prepared by polymerase chain reaction (PCR) using human TSP-1 CDNA and DIG-11-dUTP (Boehringer Mannheim). A cDNA probe for human $\beta$-actin was also prepared and used as a control.

\section{Reporter plasmid}

A 2974 bp region of the human TSP-1 gene (-2220 +754 ) was prepared from Hep3B genomic DNA by PCR using a primer set, 5'-CAACTGAAGTATCATGATAAG AG and 5'-ATCCTGTAGCAGGAAGCACAAG, and rTth DNA polymerase XL (PE Applied Biosystems, Foster City, $\mathrm{CA})$. The amplification was conducted under the following conditions: denaturation, $94^{\circ} \mathrm{C}$ for $30 \mathrm{sec}$; annealing, $50^{\circ} \mathrm{C}$ for $30 \mathrm{sec}$; extension, $72^{\circ} \mathrm{C}$ for $3 \mathrm{~min}$. The PCR product was then ligated into the $\mathrm{Kpnl}$ and $\mathrm{XhOl}$ sites of a promoterless pGL3 luciferase expression vector (Promega Co., Madison, WI).

\section{Transient transfection and reporter assay}

Cells $\left(3 \times 10^{5}\right)$ were plated in a 6 -well culture plate. The next day, the cells were transiently transfected with $2 \mu \mathrm{g}$ plasmid DNA using FuGENE 6 (Boehringer Mannheim). The pTSP-LUC, pCR3.1 coding for $\beta$-galactosidase, and the c-Jun expression vector pSG5 were used in these transfection assays. Eight hours later, the cells were washed and treated with the respective agents. After $12 \mathrm{~h}$, the cells were harvested, extracted, and subjected to luciferase assay (Boehringer Mannheim) and $\beta$-galactosidase assay (Sambrook et al., 1989). Luciferase activity was normalized to the $\beta$-galactosidase activity used as control for the efficiency of transfection. Relative luciferase activity was expressed as mean $\pm S D$ in triplicate.

\section{Electrophoretic mobility shift assay (EMSA)}

Nuclear extracts were obtained from about $3 \times 10^{6}$ cells as described by Schreiber et al. (1989) with some modification. Briefly, cells were harvested and washed once with cold CMF-PBS, and nuclear proteins were extracted in the presence of protease inhibitors including $1 \mu \mathrm{g} / \mathrm{ml}$ leupeptin, $1 \mu \mathrm{g} / \mathrm{ml}$ pepstatin, and $2 \mu \mathrm{g} / \mathrm{ml}$ aprotinin. The three double-stranded oligonucleotides used in this assay were distributed over the region of -767 to -656 of the TSP-1 promoter (oligo a, -767 to -723 ; oligo b, -734 
to -689 ; oligo $\mathrm{c},-700$ to -656$)$. The probes were endlabeled with $\left[\alpha^{-32} \mathrm{P}\right] \mathrm{dATP}$ using the Klenow fragment. Binding reactions were performed with $5 \mu \mathrm{g}$ of nuclear protein as described previously (Vincenti et al., 1992), and the samples were analyzed on a $5 \%$ polyacrylamide gel in $1 \times$ TBE buffer. The gels were vacuum-dried and then analyzed by autoradiography.

\section{Results}

\section{Effects of PMA on TSP-1 synthesis in PAE cells}

In order to confirm the PMA effect on endothelial cells, the level of TSP-1 synthesis in PAE cells was investigated and found that TSP-1 synthesis was inhibited in a dose-dependent manner upon treatment with PMA (Figure 1A). TSP-1 mRNA levels by Northern blot analysis also showed decrease in the PAE cells and suggest possible suppression of the TSP-1 gene expression. When the PAE cells were treated with $100 \mathrm{nM}$ PMA, the level of TSP-1 mRNA started to decrease after $30 \mathrm{~min}$ and steadily decreased after $6 \mathrm{~h}$. This inhibitory effect persisted at least $24 \mathrm{~h}$ (Figure 1B).

\section{Induction of c-Jun and transcriptional regulation of the TSP-1 gene promoter.}

Possilibity of PMA effect on the level of c-Jun and c-Fos, the major components of AP-1 as observed in other cell types were examined. Although the level of c-Fos ex-

(A)

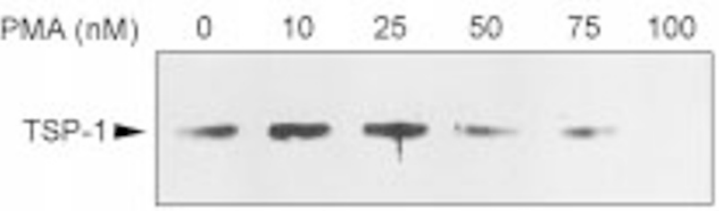

(B)
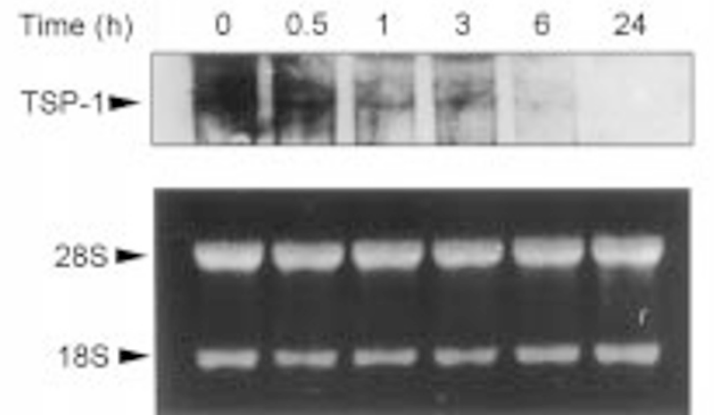

Figure 1. Regulation of TSP-1 synthesis by PMA in PAE cells. (A) Cells were incubated with the indicated concentrations of PMA for $24 \mathrm{~h}$ and the culture supernatants were analyzed by Western blot. (B) Cells were treated with $100 \mathrm{nM}$ PMA for a $24 \mathrm{~h}$ period, and total cellular RNA was extracted. Fifteen mg total RNA was used for Northern blot analysis. Ethidium bromide staining of the same gel was used to monitor nucleic acid loading in each lane.
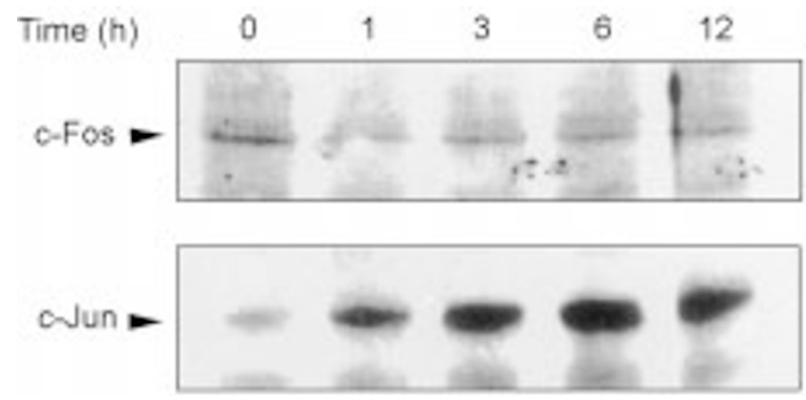

Figure 2. Induction of C-Jun in PMA-treated PAE cells. PAE cells were treated with $100 \mathrm{nM}$ PMA for the time periods indicated. The levels of c-Fos and c-Jun expression in the nuclear extract was then analyzed by Western blot. c-Fos and c-Jun positive bands were revealed using an enhanced chemiluminescence detection system.

pression did not change, the level of c-Jun increased dramatically upon PMA treatment (Figure 2). After the addition of PMA, the C-Jun level started to increase within $1 \mathrm{~h}$, and the increased level was sustained for $12 \mathrm{~h}$

To determine whether the inhibition of TSP-1 expression occurred through the regulation of a cis-acting element in the TSP-1 promoter, we constructed a reporter plasmid which consisted of the TSP-1 promoter region $(-2220$ to +754$)$ linked to a promoterless luciferase gene. PAE cells were transiently transfected with this TSP-Luc reporter plasmid and the effect of PMA on the reporter expression was examined. TSP-1 promoter-mediated luciferase activity was declined to 0.32 fold of control activity following treatment with $100 \mathrm{nM}$ PMA for $12 \mathrm{~h}$ in the transfected PAE cells (Figure 3). Since PMA dramatically induced c-Jun expression in PAE cells (Figure 2 ), an affect of the c-Jun expression on TSP-1 promoter

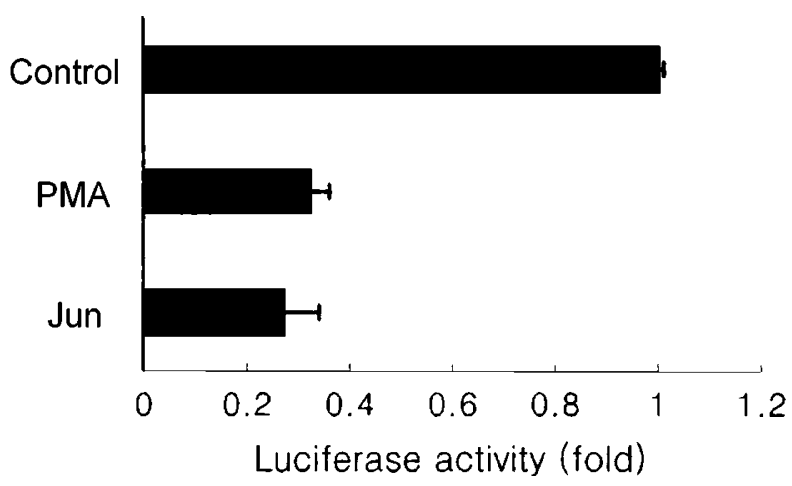

Figure 3. Transcriptional inhibition of a TSP-Luc reporter plasmid by PMA and c-Jun in PAE cells. Cells were transiently transfected with TSP-Luc reporter plasmid alone or in combination with a c-Jun expression plasmid. After transfection, cells were left untreated (control and c-Jun transfectant) or treated with $100 \mathrm{nM}$ PMA for $12 \mathrm{~h}$. Luciferase activity is expressed relative to the luciferase activity obtained from the untreated control cells. The luciferase activity was normalized to the cotransfected $\beta$-gal activity. These data represent the mean $\pm S D$ of three independent experiments. 


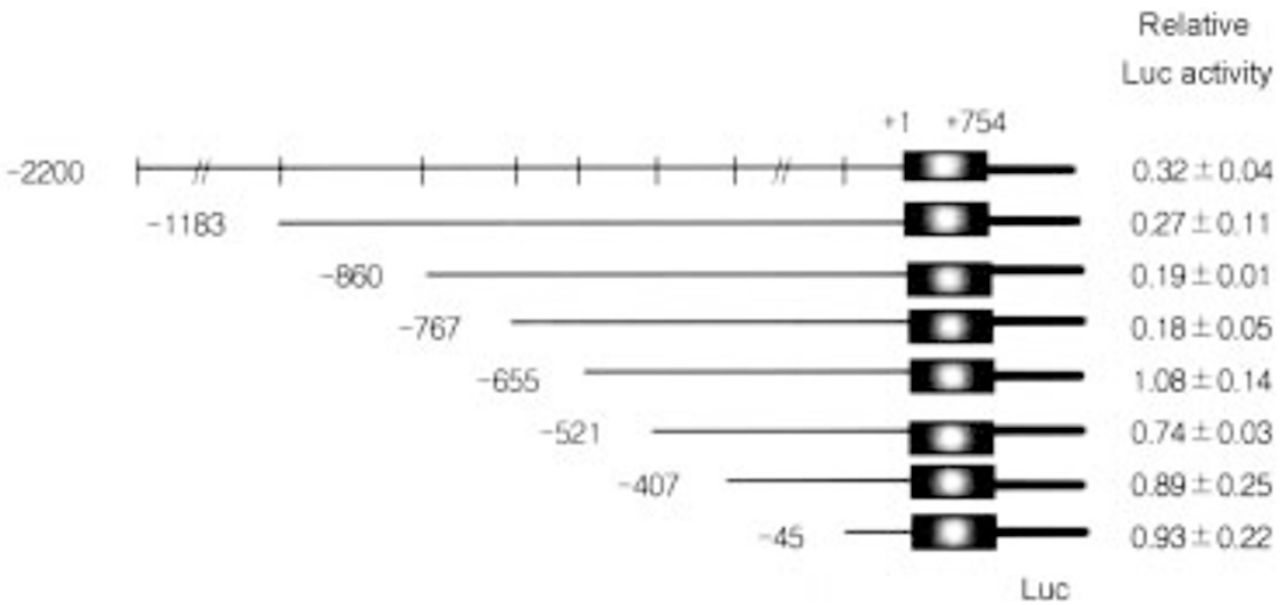

Figure 4. Structure and activity of various deletion fragments of the TSP-1 promoter. PAE cells were transfected with each deletion construct. After $8 \mathrm{~h}$, the cells were treated with $100 \mathrm{nM}$ PMA, and luciferase activity was assayed after $12 \mathrm{~h}$. The luciferase activity of each plasmid is expressed relative to the luciferase activity obtained from the untreated control cells. The luciferase specific activity of each construct was normalized to the cotransfected $\beta$-gal activity. The data represent the mean \pm SD of three independent experiments.

activity was also tested. As shown in Figure 3, the cells contransfected with the TSP-Luc reporter plasmid in combination with a c-Jun expression vector, showed reduced luciferase activity by 0.3 fold in comparison with that of control activity, which is similar to what we observed in the PMA treated cells. The results suggested that the decrease in TSP-1 synthesis induced by PMA was due to transcriptional regulation and that the TSP-1 gene must contain some regulatory element which is affected by c-Jun expression.

\section{Identification of regulatory elements for the inhibi- tion of TSP-1 expression}

In order to determine which sequence on the promoter was involved in the repression of TSP-1 expression, PAE cells were transiently transfected with the TSP-Luc plasmid $(-2220$ to +754$)$ or deletion constructs thereof. Deletion of the TSP-1 promoter region up to $-768 \mathrm{did}$ not modify the transcriptional repression by PMA (Figure 4). However, further deletion, up to -656 , abolished the response to PMA. The same results were obtained from the cells cotransfected with the c-Jun expression vector (data not shown).

Since the binding of nuclear protein(s) to a cis element may cause the PMA-dependent repression of the TSP1 gene expression and because the region between -767 and -656 contained no known AP-1 responsive element, any protein binding to this region was examined by EMSA. Three overlapping fragments were used as probes: oligo $a ;-767$ to -723 , oligo $b$; -734 to -689 , and oligo $\mathrm{c} ;-700$ to -656 . A specific shift of band was observed only with oligo $a$. When the cells were treated with PMA, this band shift disappeared in a time depen-

\section{(A)}

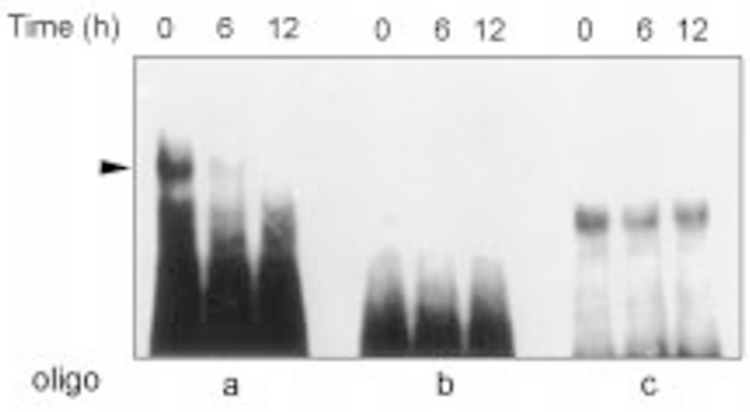

(B)

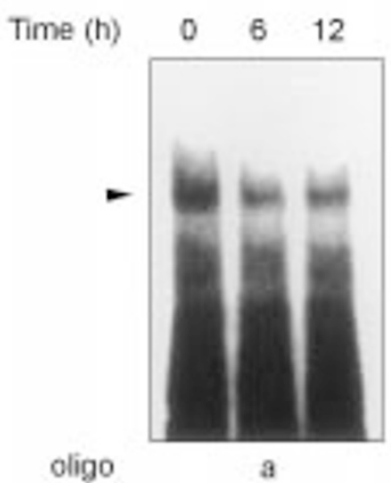

Figure 5. EMSA of nuclear extract binding to the TSP-1 promoter region -767 to -656 . PAE (A) and Hep3B (B) cells were treated with $100 \mathrm{nM}$ PMA for the indicated time periods and nuclear extracts were prepared. Ten $\mu \mathrm{g}$ of nuclear protein was combined with $\left[\alpha^{-}{ }^{32} \mathrm{P}\right] \mathrm{dATP}$-labeled oligo $\mathrm{a}, \mathrm{b}$, and $\mathrm{c}$ and analyzed by EMSA as described in "Materials and Methods." The arrow head points to the specifically shifted bands. Oligo a, -767 to -723 ; oligo b, -734 to -689 ; oligo c, -700 to -656 . 
dent manner (Figure 5A), which decrease at $6 \mathrm{~h}$ and completely faded away at $12 \mathrm{~h}$. On the other hand, no significant change was observed in a DNA-protein complex in Hep 3B cell extracts (Figure 5B). A computer analysis revealed the potential presence of $\mathrm{Sp} 1$ and GATA-1 binding sites in this region (-767 to -735$)$. To find out whether these nuclear proteins could indeed bind to this region, we performed EMSA using Sp1, GATA-1, and AP-1 antibodies. But the protein band, whose level was diminished upon PMA treatment, was not affected by any of these antibodies (data not shown). This result suggests that Sp1, GATA-1, and AP1 transcription factors were not responsible for the PMAdependent inhibition of TSP-1 expression in PAE cells.

\section{Discussion}

Increasing number of the data strongly support a role of TSP-1 as a negative regulator of solid tumor progression and angiogenesis. Understanding regulation of TSP1 expression thus may provide insights into a new approaches to cancer therapy. Although several factors known to affect TSP-1 expression, the regulatory mechanism of the TSP-1 gene expression is not well understood. Among the factors effecting TSP-1 expression, PMA exhibited a typical cell type inhibitory agent in a specific effectiveness.

In human hepatocarcinoma Hep 3B cells, we found that PMA markedly stimulated TSP-1 synthesis. In addition, the regulatory mechanism of the tsp-1 gene expression was found to involve the activation of PKC and the transcription factor AP-1 which were the critical events in the PMA-mediated tsp-1 gene activation. Tsp1 gene promotor has a functional AP-1 binding site, and it is activated via the increased expression of C-Jun in Hep 3B cells.

Interestingly, PAE cells treated with PMA showed inhibition of TSP-1 synthesis in a dose-dependent manner via the PKC pathway. The fact that C-Jun overexpression in cells transfected with an expression vector resulted in inhibition of TSP-1 expression, suggested that this repression may be linked to transcriptional control by CJun. But experiments with serial deletions of the TSP-1 promoter demonstrated that TSP-1 repression by c-Jun did not utilize any of the known AP-1 sites present in the TSP-1 promoter. Instead, we identified a 33 bp region, -767 to -735 that was responsive to the negative regulation of TSP-1 transcription. A computer analysis revealed the presence of several potential regulatory elements, including Sp1 and GATA-1 in this region. However, supershift assays with antibodies against Sp1 or GATA1 demonstrated that these transcription factors were not responsible for the PMA induced down-regulation of TSP-1 (data not shown). Supershift experiments with anti-AP-1 antibody reconfirmed that AP-1 did not bind to this 33-bp region.

The interaction between DNA binding proteins and cis-acting elements plays an important role in controlling gene expression. The same DNA sequence may function as either a positive or negative control element depending on the DNA binding factors present in different cell types or stages of differentiation. Although the PMAresponsive regulatory factor of TSP-1 exists in both PAE and Hep 3B cells, PMA treatment suppressed its binding activity only in PAE cells (Figure 5). Our results indicate that c-Jun does not participate directly in the repression of TSP-1 transcription by binding to its promoter. Recently, PMA-responsive down-regulatory factors, thyroid transcription factor 1 (TTF-1) and hepatocyte nuclear factor 3 (HNF3), have been reported (Kumar et al., 1997). But, the consensus motif was different from any nucleotide sequence in the 33-bp region of TSP-1.

A c-Jun homodimer can bind to other proteins or transcriptional coactivators. AP-1 requires transcriptional coactivator CBP, CAMP response element-binding protein (CREB) binding protein for its transcriptional activation (Arias et al., 1994; Bannister et al., 1995). It is possible that the unknown factor bound to the 33-bp region may require another protein for stability. C-Jun and the unknown factor may compete for the same transcriptional coactivator. It has been demonstrated that both AP-1 and retinoic acid receptor (RAR) require CREB for their transcriptional activation, and because of competition for CREB, they were regulated in opposite ways (Willy et al., 1995; Soprano et al., 1996). To elucidate this unknown factor, the PMA-dependent down-regulation of TSP-1 gene expression is currently under further investigation.

In summary, we demonstrated that TSP-1 expression is effectively inhibited by PMA in PAE cells. In this PMA induced inhibition of TSP-1 expression, c-Jun does not participate directly in the repression of TSP-1 transcription by binding to its promoter, but this effect may be mediated by another regulatory factor which could bind to the -767 to -735 region of the promoter.

\section{Acknowledgement}

This study was supported by a grant from the Basic Research Promotion Fund of the Ministry of Education, Korea for 1998.

\section{References}

Angel, P., Allegretto, E. A., Okino, S. T., Hattori, K., Boyle, W. J., Hunter, T. and Karin, M. (1988) Oncogene jun encodes a sequence-specific trans-activator similar to AP-1. Nature 332: 166-171

Angel, P. and Karin, M. (1991) The role of Jun, fos and the 
AP-1 complex in cell proliferation and transformation. Biochim. Biophys. Acta 1072: 129-157

Arias, J., Alberts, A. S., Brindle, P., Claret, F. X., Smeal, T., Karin, M., Feramisco, J. and Montminy, M. (1994) Activation of cAMP and mitogen responsive genes relies on common nuclear factor. Nature 370: 226-229

Bannister, A. J., Oehler, T., Wilhelm, D., Angel, P. and Kouzarides, T. (1995) Stimulation of C-Jun activity by CBP: cJun resides Ser $63 / 73$ are required for CBP induced stimulation in vivo and CBP binding in vitro. Oncogene 11: 2509-2514

Bellon, G., Chaqour, B., Antonicelli, F., Wegrowski, J., Claisse, D., Haya, B. and Borel, J-P. (1994) Differential expression of thrombospondin, collagen, and thyroglobin by thyroid-stimulating hormone and tumor-promoting phorbol ester in cultured porcine thyroid cells. J. Cell Phsiol. 160: 75-88

Bohmann, D., Bos, T. J., Admon, A., Nishimura, T., Vogt, P. K. and Tjian, R. (1987) Human proto-oncogene c-jun encodes a DNA binding protein with structural and functional properties of transcription factor AP-1. Science 238: 1386-1392

Bornstein, P. (1992) Thrombospondin: structure and regulation of expression. FASEB J. 6: 3290-3299

Bornstein, P. (1995) Diversity of function is inherent in matricellular proteins: an appraisal of thrombospondin 1. J. Cell. Biol. 130: 503-506

Chua, C. C., Hamdy, R. C. and Chua, B. H. L. (1997) Regulation of thrombospondin-1 production by angiotensin II in rat heart endothelial cells. Biochim. Biophy. Acta 1357: 209-214

Clezardin, P. (1993) Thrombospondin, pp. 41-61, CRC Press, Boca Raton, FL

Dejong, V., Degeorges, A., Filleur, S., Ait-Si-Ali, S., Mettouchi, A., Bornstein, P., Binetruy, B. and Cabon, F. (1999) Wilms tumor gene product represses the transcription of thrombospondin 1 in response to overexpression of c-Jun. Oncogene 18: 3143-3151

Kumar, A. S., Venkatesh, V. C., Planer, B. C., Feinstein, S. I. and Ballard, P. L. (1997) Phorbol ester down-regulation of lung surfactant protein $B$ gene expression by cytoplasmic trapping of thyroid transcription factor-1 and hepatocyte nuclear factor 3. J. Biol. Chem. 272: 20764-20773

Laemmli, U. K. (1970) Cleavage of structural proteins during the assembly of the head of bacteriophage T4. Nature 227:
$680-685$

Lahav, J. (1993) The functions of thrombospondin and its involvement in physiology and pathophysiology. Biochim. Biophys. Acta 1182: 1-14

Lawler, J. (1986) The structural and functional properties of thrombospondin. Blood 67: 1197-1209

Mettouchi, A., Cabon, F., Montreau, N., Vernier, P., Mercier, G., Blangy, D., Tricoire, H., Vigier, P. and Binetruy, B. (1994) SPARC and thrombospondin genes are repressed by the $\mathrm{C}$ jun oncogene in rat embryo fibroblasts. EMBO J. 13: 56685678

Mosher, D. F. (1990) Physiology of thrombospondin. Annu. Rev. Med. 41: 85-97

Sambrook, J., Fritsch, E. F. and Maniatis, T. (1996) Molecular cloning: A laboratory manual, 2nd Eds., pp. 16.66-16.67, Cold Spring Harbor Laboratory Press, Cold Spring Harbor, NY

Schreiber, E., Matthias, P., Muller, M. M. and Schaffner, W. (1989) Rapid detection of octamer binding proteins with miniextracts, prepared from a small number of cells. Nucl. Acids Res. 17: 6419

Soprano, D. J. R., Chen, L. X., Wu, S., Donigan, A. M., Borghaei, R. C. and Soprano, K. J. (1996) Overexpression of both RAR and RXR restores AP-1 repression in ovarian adenocarcinoma cells resistant to retinoic acid-dependent inhibition. Oncogene 12: 577-584

Varani, J., Riser, B. L, Hughes, L. A., Carey, T. E., Fligiel, S. E. G. and Dixit, V. M. (1989) Characterization of thrombospondin synthesis, secretion and cell surface expression by human tumor cells. Clin. Exp. Metastasis 7: 265-276

Vincenti, M. P., Burrell, T. A. and Taffet, S. M. (1992) Regulation of NF- $\mathrm{KB}$ activity in murine macrophage: Effect of bacterial lipopolysaccharide and phorbol ester. J. Cell Physiol. 150: 204-209

Willy, P. J., Umesono, K., Ong, E. S., Evans, R. M., Heyman, R. A. and Mangelsdorf, D. J. (1995) LXR, a nuclear receptor that defines a distinct retinoid response pathway. Genes Dev. 9: $1033-1045$

Yesner, L. M., Huh, H. Y., Pearce, S. F. and Silverstein, R. L. (1996) Regulation of monocyte CD36 and thrombospondin-1 expression by soluble mediators. Arterioscler. Thromb. Vasc. Biol. 16: 1019-1025 